\title{
Subsídios para Elaboração de um Tesauro Brasileiro de Turismo $^{1}$
}

\author{
Foundations for the Establishment of a Brazilian Thesaurus for Tourism
}

Fundamentos Hacia la Elaboración de un Tesauro Brasileño de Turismo

\author{
Mirian Rejowski ${ }^{2}$ \\ Nair Yumiko Kobashi ${ }^{3}$
}

\begin{abstract}
Resumo
Apresentação de parâmetros e requisitos para a elaboração de um Tesauro Brasileiro de Turismo, instrumento terminológico para padronizar, por meio de um vocabulário controlado sistêmico, as formas de representar os conteúdos de trabalhos acadêmicos. Caracteriza-se, inicialmente, a natureza, estrutura e funções de um tesauro e sua importância e papel no campo dos estudos do Turismo. A estruturação categórica preliminar do campo do Turismo, aqui proposta, foi feita com base: nos estudos de Rejowski sobre as teses brasileiras em Turismo; em tesauros da OMT e do Instituto de Estudos Turísticos do Ministério da Economia da Espanha; em conceitos sistematizados por Lohmann e Panosso Netto; em índices de assuntos do Annals of Tourism Research e Estudios y Perspectivas en Turismo e consultas a pesquisadores da área.
\end{abstract}

Palavras-chave: turismo; tesauro; classificação de termos turísticos; Brasil.

\section{Abstract}

Presentantion of parameters and requirements to develop a Brazilian Thesaurus of Tourism, a controlled vocabulary to standardize the terminology of scholarly works. It is characterized first the nature, structure and functions of a thesaurus and its importance and role in the Tourism field studies. The categorical structure proposed is based on: the studies of Rejowsky on Brazilian dissertations; the thesauri of WTO and of the Instituto de Estudios Turisticos of Spain; the subjects of Annals of Tourism Research and Estudios y Perspectivas en Turismo.

\footnotetext{
${ }^{1}$ Trabalho apresentado no I Seminário Internacional de Estudos Críticos em Turismo realizado nos dias 24 e 25 de março de 2011, organizado pelo grupo de pesquisa Estudos Críticos em Turismo - ESCRITUR/UFRN/CNPq.

${ }^{2}$ Bacharel em Turismo, Mestre e Doutora em Ciências da Comunicação e Livre Docente em Teoria do Turismo e do Lazer pela Universidade de São Paulo. Professora titular do Mestrado em Hospitalidade da Universidade Anhembi Morumbi. Pesquisadora do CNPq. E-mail: mirwski@gmail.com.

${ }^{3}$ Bacharel em Biblioteconomia, Bacharel em Jornalismo. Mestre e Doutora em Ciências da Comunicação pela Universidade de São Paulo. Professora Livre-docente da Escola de Comunicações e Artes da Universidade de São Paulo. Pesquisadora do CNPq. E-mail: nykobash@usp.br.
} 


\section{TURISMO EM ANÁLISE}

Keywords: tourism; thesaurus; tourism terms classification; Brazil.

\section{Resumen}

Presentación de estandares y requisitos para la proposición de un Tesauro Brasileiro de Turismo, instrumento terminológico para categorizar, por medio de uno vocabulario controlado sistémico, las formas de representar los contenidos de trabajos académicos. Caracteriza-se, primeramente, la naturaleza, estructura y funciones de un tesauro y su importancia e papel no campo dos estudos do Turismo. La estructuración categórica preliminar del campo del Turismo propuesta en este trabajo esta basada en los estudios de Rejowski sobre las tesis brasilenas en Turismo; en los tesauros de la OMT y del Instituto de Estudios Turísticos del Ministério de Economia de Espana; en conceptos sistematizados por Lohmann y Panosso Netto; en indices de temas del Annals of Tourism Research y Estudios y Perspectivas en Turismo; y encuestas con investigadores de la área.

Palavras-chave: turismo; tesauro; clasificación, terminos turísticos; Brasil.

\section{Introdução}

Nas pesquisas do campo do Turismo, é comum serem apontadas dificuldades para classificar tematicamente a produção científica brasileira. O problema é, em geral, atribuído à ausência de vocabulários controlados para indexar de forma padronizada as dissertações, teses, artigos de periódicos e trabalhos apresentados em eventos.

Esse fato, motivo de preocupação exposta na primeira pesquisa sobre o tema de Rejowski (1993), persiste ainda hoje, como mostram os estudos de mapeamento temático da área (MOON, 2009; REJOWSKI, 2010), e discussões em eventos científicos, em especial no I Seminário Internacional de Estudos Críticos em Turismo, realizado em março de 2011 sob a promoção e organização da Universidade Federal do Rio Grande do Norte. Observa-se, pois, que a ausência de dados temáticos padronizados coloca problemas à comparação e, em decorrência, à interpretação rigorosa das pesquisas turísticas.

Pesquisas de mapeamento temático são, portanto, imprescindíveis para reconhecer pontos fortes e fracos de uma área de pesquisa. Sem essa identificação, torna-se difícil tanto analisar de forma sistemática a produção científica da área, quanto elaborar políticas de pesquisa 


\section{TURISMO EM ANÁLISE}

científica. Daí a importância das pesquisas de metaciência, como expressado por Galemberck (1990, p. 627-629), pois elas

[...] permitem analisar e avaliar a qualidade e efetividade do conhecimento produzido em uma determinada área, bem como suas necessidades e déficits. $\mathrm{O}$ próprio progresso científico se relaciona ou depende de avaliações sistemáticas da produção e do trabalho dos pesquisadores, o que garante o aperfeiçoamento constante não só do conhecimento, como também do próprio ensino.

O Turismo é um campo de estudos e pesquisas de caráter multi, inter e transdisciplinar, realizado no âmbito das Ciências Sociais Aplicadas, embora não restrito a este domínio (REJOWSKI, 2010). Estudiosos como Jafari e Ritchie (1981), Rejowski (1993, 1997) e Schlüter (2000) citam pesquisas sobre Turismo nas mais diversas áreas ou campos, tais como: Administração, Antropologia, Ciência Política, Comunicação, Direito, Ecologia, Economia, Geografia, Psicologia e Sociologia, Arquitetura, Engenharia e até Medicina.

O interesse em analisar a produção científica em Turismo teve início na década de 1980, com a pesquisa pioneira de Jafari e Aaser (1988), cujo objeto de estudo foram as teses de doutorado produzidas entre 1951 e 1987 nos Estados Unidos. Essa pesquisa estimulou a realização de estudos similares em vários países, como os de Hall (1991) na Austrália, Botterill (2002) no Reino Unido, e Santos (2010) em Portugal.

No Brasil, o primeiro estudo sistemático sobre as temáticas das dissertações e teses sobre Turismo foi desenvolvido na primeira metade da década de 1990 por Rejowski (1993), com um corpus composto de 55 pesquisas acadêmicas. Cinco anos mais tarde, este estudo foi revisto e ampliado para 102 pesquisas (REJOWSKI, 1997), com uma nova classificação temática de teses e dissertações, tendo por base o sistema de turismo (SISTUR) proposto por Beni (1988). Novos estudos se seguiram, inaugurando, no caso brasileiro, um ciclo virtuoso de novas pesquisas sobre os temas do Turismo (SAKATA, 2002; GOMES, 2004; BASTOS, 2005 e 2008; PINTO; BABINSKI, 2006; FIGUEIREDO; BACON; REJOWSKI, 2007; FEDRIZZI, 2008; SPOLON; MOTODA, 2008; POSSAMAI; MARINHO; SANTOS, 2010, dentre outras). 


\section{TURISMO EM ANÁLISE}

Deve-se assinalar também a constituição do grupo de trabalho Produção Científica em Turismo e Hospitalidade, a partir de 2008, nos seminários da Associação Nacional de Pesquisa e Pós-Graduação em Turismo (ANPTUR), e de grupos de pesquisa, especialmente o Grupo de Estudos Críticos em Turismo (ESCRITUR), vinculado ao Mestrado em Turismo da UFRN. Tais fatos demonstram o interesse da comunidade científica tanto em investigar e compreender o estado da arte do conhecimento científico em Turismo produzido no Brasil, quanto em analisar criticamente o mesmo. É neste contexto que se justifica a elaboração deste artigo como "um primeiro passo" para o Tesauro Brasileiro de Turismo, ferramenta que tem por função padronizar, por meio de um vocabulário controlado sistêmico, as formas de representar os conteúdos dos trabalhos produzidos na área ou campo.

Tem-se por objetivo estimular a discussão acerca de termos representativos do conhecimento turístico produzido no Brasil, que poderão orientar a organização e estrutura de um futuro tesauro. Trata-se de um estudo exploratório sobre o tema, de caráter bibliográfico, fundamentado especialmente em: pesquisas de Rejowski (2010) sobre as teses de doutorado sobre Turismo produzidas no Brasil de 1990 a 2005, e de Santos (2010) sobre a investigação turística nas universidades portuguesas; tesauros da área (OMT, 2001; ESPAÑA, 2003); conceitos e abordagens teóricas sistematizadas por Lohmann e Panosso Netto (2008); índices de assuntos (com base em palavras-chave de artigos) de periódicos (Annals of Tourism Research e Estudios y Perspectivas en Turismo) e contato com pesquisadores da área.

Com tal propósito, este artigo apresenta o conceito de tesauro e sua forma de organização, e esclarece sua importância e papel no campo do Turismo. Em seguida, propõe uma primeira estruturação categórica do campo para discussão junto à comunidade científica e encaminhamento de novas pesquisas.

\section{Tesauros: conceituação e funções}

O tesauro para fins documentários surgiu na década de 1960, como instrumento para indexar e recuperar informação, tendo como princípio norteador o controle semântico dos termos (GOMES, 1996). 


\section{TURISMO EM ANÁLISE}

Um tesauro pode, em uma primeira aproximação, ser definido como uma lista normalizada e estruturada de termos autorizados, chamados descritores, para indexar conteúdos de documentos, de modo a facilitar o armazenamento e a busca de informações (CACALY et al. 2001). O tesauro é caracterizado também como uma linguagem artificial constituída de termos organizados em estrutura relacional. Uma de suas funções é representar a informação e o conhecimento por meio de um conjunto padronizado de termos, denominados descritores. São essas características que fazem dele um instrumento "potente" para identificar e recuperar informação armazenada em sistemas e unidades de informação (bases de dados bibliográficos, repositórios de artigos e trabalhos acadêmicos, bibliotecas). Os tesauros começaram a ser elaborados a partir da constatação de que são variadas as possibilidades de nomear fatos, processos, fenômenos ou objetos. A título de exemplo: os termos Agricultores e Comunidade rural podem ser considerados sinônimos em certas situações, o mesmo podendo ocorrer com os termos Impactos turísticos e Efeitos do turismo.

Esse fenômeno mostra a riqueza de uma língua, indicando também que a linguagem é sempre ideológica. Porém, o uso indiscriminado desses termos como palavras-chave de artigos, ou na indexação de informação armazenada em base de dados, promove dispersão de documentos que apresentam temas semelhantes. Esse fato foi apresentado como problema preocupante nas pesquisas de Rejowski (1993 e 1997) por ter tornado árdua a tarefa de coletar dados empíricos para mapear os temas das pesquisas turísticas. Com essa mesma preocupação, Moom e Santos (2010, p. 376) ressaltam que o tesauro "pode auxiliar, não só na recuperação da informação, mas também na representação do conhecimento científico produzido", organizando e sistematizando o estado da arte do conhecimento em Turismo.

Os tesauros, portanto, propõem formas padronizadas de caracterizar e nomear informação, identificando as diferentes denominações de objetos e fenômenos e organizando-os em rede relacional para que apontem, invariavelmente, para o conjunto de informações semelhantes, independentemente das variantes terminológicas utilizadas (AUSTIN, 1993). Desse modo, admite-se que os resultados das buscas serão tanto mais consistentes quanto maior a coincidência entre as formas de representação de informação utilizadas pelo sistema de 


\section{TURISMO EM ANÁLISE}

informação e pelo usuário. Dito de outra maneira, a utilização de um tesauro pretende garantir uma melhor comunicação entre sistema de informação e usuário.

Um tesauro é composto de um conjunto de termos que representam os conceitos de um ou vários domínios de conhecimento. Assim, podem existir tesauros de Economia, de Cultura popular, de Saúde, de Metalurgia, de Psicologia, de Turismo; ou seja, podem ser elaborados tesauros sobre grandes áreas de conhecimento, como Turismo, ou de subdomínios de uma área, como a Hotelaria por exemplo. Em todos os casos, porém, os seus termos são dispostos em uma estrutura relacional previamente definida, em geral distribuídos em grandes classes temáticas de assuntos (categorias). Cada termo, por sua vez, é associado aos demais termos do tesauro com os quais mantém relações de natureza lógico-semântica.

Em um tesauro, são estabelecidas, além das relações de sinonímia, as redes hierárquicas entre os termos, para possibilitar recuperação de informação em diferentes níveis de agregação. Em suma, são especificados os valores do termo dentro do sistema por meio de operadores semânticos (gênero/espécie; todo-parte; equivalência, associação espacial ou temporal, etc.). Padronizar os termos utilizados em um sistema de informação é, portanto, a função básica dos tesauros.

Evita-se, com o uso do tesauro, a localização de informações pouco pertinentes, ou mesmo não-pertinentes. Não encontrar informação que se supõe armazenada, ou ter dúvidas sobre a integridade da informação encontrada, ou receber como resposta "tudo" que está armazenado, é certamente um defeito encontrado nos sistemas que utilizam vocabulário livre.

Finalmente, sua construção não é tarefa individual. É atividade coletiva que requer a participação dos gestores e dos usuários do sistema de informação. Não é, também, uma linguagem acabada. Ela deve ser objeto de atualização periódica, de modo a refletir a dinâmica das atividades que se propõe nomear e organizar.

A análise e a construção de tesauros orientam-se por diferentes abordagens e perspectivas, sejam elas políticas, ideológicas, teóricas e/ou metodológicas. Salienta-se que o desenvolvimento das tecnologias da informação deu margem a abordagens que consideram supérfluas ou mesmo pouco úteis as operações de tratamento da informação por meio de 


\section{TURISMO EM ANÁLISE}

linguagens de organização da informação. No entanto, o crescimento exponencial de informações disponíveis nas redes eletrônicas recoloca a necessidade do uso de ferramentas de tratamento semântico de informação - os diferentes tipos de linguagens documentárias para tratar informação, dentre elas os tesauros.

Nesta última perspectiva, as linguagens documentárias são consideradas fundamentais, pois sem elas haverá ruídos indesejáveis na comunicação e fluxo de informações armazenadas em bases de dados bibliográficos. Em síntese, os tesauros são mecanismos de mediação que apresentam ao menos duas funções: representar o conhecimento inscrito e promover interação entre usuário e dispositivos de informação (KOBASHI, 1996, 2007). Nesta perspectiva, não são nomenclaturas ou listas de palavras e expressões para etiquetar documentos, mas sim instrumentos essenciais para estabelecer interação e diálogo entre sistemas de informação e usuários incorporando a linguagem do usuário.

Os tesauros são constituídos de unidades especiais: os nomes e os sintagmas nominais ou, mais precisamente, unidades polilexicais que designam fenômenos e objetos de campos especializados. Para serem funcionais, tornam explicitas as relações entre os termos que as constituem.

As relações entre as unidades do tesauro, termos denominados descritores e não-descritores, são determinadas por força do sistema nocional. Refletem as relações conceituais do campo nocional de origem por meio de diversos tipos de operadores semânticos e de valores que estabelecem relações entre os termos (sinonímia, hierarquia e outros tipos de associações) expressas por meio de notação apropriada: a) Termo genérico -TG; b) Termo Específico TE; c) Termo equivalente - USE e Usado Para, relações espaciais e temporais, Termo relacionado - TR. O quadro 1 discrimina as relações entre diferentes tipos de termos do tesauro e exemplifica-os com termos de Turismo. 
Quadro 1 - Relações estabelecidas entre termos do tesauro e exemplos de cada tipo de termo

\begin{tabular}{l|l|l}
\hline \multirow{2}{*}{$\begin{array}{c}\text { Relação entre termos } \\
\text { do tesauro }\end{array}$} & \multicolumn{2}{c}{ Termo } \\
\cline { 2 - 3 } & \multicolumn{1}{c}{ Tipo } & \multicolumn{1}{c}{ Exemplo } \\
\hline $\begin{array}{l}\text { Hierárquica: } \\
\text { superordenação e } \\
\text { subordinação entre } \\
\text { termos }\end{array}$ & $\begin{array}{l}\text { Termo Genérico: termo que representa o } \\
\text { conceito mais abrangente }\end{array}$ & TG Educação e formação turística \\
\cline { 2 - 3 } & $\begin{array}{l}\text { Termo específico: termo subordinado ao } \\
\text { termo genérico }\end{array}$ & $\begin{array}{l}\text { TG Planejamento turístico } \\
\text { TE Inventário da oferta }\end{array}$ \\
\hline $\begin{array}{l}\text { Associativa: } \\
\text { proximidade de } \\
\text { significados entre termos }\end{array}$ & $\begin{array}{l}\text { Termo relacionado: um termo indica outro } \\
\text { sem ser sinônimo ou subordinado a outro }\end{array}$ & $\begin{array}{l}\text { TE Roteiro turístico } \\
\text { TR Pacote turístico }\end{array}$ \\
\hline $\begin{array}{l}\text { Equivalência: termos } \\
\text { que apresentam o mesmo } \\
\text { conceito; sinônimos ou } \\
\text { equivalentes }\end{array}$ & $\begin{array}{l}\text { USE: termo autorizado para representar } \\
\text { um conceito } \\
\text { UP: termo não autorizado para representar } \\
\text { um conceito }\end{array}$ & $\begin{array}{l}\text { Atrativo turístico } \\
\text { USE Atração turística }\end{array}$ \\
\hline
\end{tabular}

Fonte: Elaboração própria.

Com esses recursos de explicitação, os tesauros permitem que o usuário (indexador ou usuário final dos sistemas de informação) transite pelos conceitos para selecionar o mais adequado para designar um fenômeno ou coisa. Os mecanismos de fixação do sentido de cada uma das suas unidades procuram, portanto, tornar explícitas as relações entre os conceitos de um domínio, de modo a aproximar as instâncias enunciativas de tratamento e de busca de informações.

Os tesauros, por outro lado, requerem atualização permanente, de modo a seguir pari-passu a dinâmica da criação terminológica do campo ao qual procura servir. Para serem úteis devem, portanto, acompanhar a evolução do campo ou área de conhecimento científico.

\section{Em Busca de um Tesauro Brasileiro de Turismo}

A caracterização do domínio de aplicação é a primeira tarefa de um projeto e elaboração de tesauros. No caso do Turismo, essa caracterização não é uma tarefa fácil, pois há diversas 
visões, desde as mais abrangentes até as mais específicas, restritas ou não a determinadas áreas do conhecimento ou a segmentos do mercado. Para os fins deste artigo, citam-se algumas abordagens que mostram de um lado a complexidade em se definir Turismo tanto como fenômeno quanto como atividade, mas de outro esclarecem a abrangência desse emergente campo de estudo e pesquisa, nas quais o Turismo é visto como:

[...] de um lado, conjunto de turistas; por outro, os fenômenos e as relações que [... estes produzem] em conseqüência de suas viagens. [...] todo o equipamento receptivo de hotéis, agências de viagens, transportes, espetáculos, guias-intérpretes [...]. [...] organizações privadas ou públicas que surgem para normatizar o mercado, fomentar a infra-estrutura e a expansão do núcleo receptor [...]. (FERNÁNDEZ FUSTER, 1971, p. 32)

[...] combinação complexa de inter-relacionamentos entre produção e serviços, em cuja composição [integra-se] uma prática social com base cultural, com herança histórica, a um meio ambiente diverso, cartografia natural, relações sociais de hospitalidade, troca de informações interculturais. (MÖESCH, 1999, p. 9)

[...] conjunto de atividades, fenômenos e relações existentes nos deslocamentos $[\ldots]^{4}$, realizados pelo afastamento da morada permanente por diferentes motivos - com intenção de retorno, e a utilização total ou parcial de bens e serviços orientados para a satisfação dos viajantes. (BACAL, 2003, p. 113)

Deixando de lado uma discussão conceitual, interessa compreender a abrangência do conhecimento produzido em Turismo. Rejowski (2010), em pesquisa acerca da produção de teses sobre Turismo no Brasil, no período de 1990 a 2005, observou vinte áreas produtoras, distribuídas por todas as grandes áreas do conhecimento. Dentre essas se destaca a área de Ciências Sociais Aplicadas, confirmando o disposto por Jafari e Aaser (1988) ao estudarem as teses sobre Turismo nos Estados Unidos; e, dentre as áreas com maior produção estavam a Comunicação e a Geografia, seguidas da Administração, Engenharia e Sociologia.

Embora ainda prevaleça o paradigma sistêmico nas pesquisas turísticas, fundamentadas principalmente no SISTUR (BENI, 2001), percebem-se movimentos em direção a novas

\footnotetext{
${ }^{4}$ Excluiu-se da definição de Sarah Bacal o adjetivo "voluntário" para o deslocamento, pois na atualidade há deslocamentos não totalmente voluntários no âmbito de segmentos como os de saúde e de negócios, que podem ser considerados turísticos ou não conforme a abordagem adotada pelo pesquisador. Também o uso do termo viajante amplia o conceito para o campo das viagens e turismo.
} 


\section{TURISMO EM ANÁLISE}

abordagens envolvendo, por exemplo, releituras do paradigma sistêmico e propostas inovadoras relacionadas à sustentabilidade, ética, complexidade e hospitalidade (FARREL; TWINING-WARD，2004; MCBETH，2005; SOGAYAR，2010) em busca de novos paradigmas a nortear os estudos turísticos.

Embora as pesquisas acadêmicas sobre o Turismo no Brasil tenham se iniciado somente no início da década de 1970 (REJOWSKI, 1997), já pode ser detectada quantidade significativa de publicações que indica, de um lado, uma relevante e significativa produção científica sobre Turismo, e, de outro, a necessidade de organização e sistematização desse conhecimento, reforçando assim a importância e papel de um tesauro específico da área.

As Diretrizes de elaboração de tesauros (AUSTIN, 1993) e a Norma ANSI (ANSI/NISO, 2005) são fontes largamente utilizadas para dar suporte metodológico à sua elaboração. Além dessas normas, recorre-se, também a obras que exploram os aspectos teóricos ou metodológicos envolvidos na tarefa, como as de Austin (1993) Gomes (1996a e 1996b) e Cintra et al. (2002).

As diretrizes e normas recomendam que se dê início ao trabalho com a identificação de outros vocabulários controlados que possam servir de pontos de partida para a coleta de termos. Está presente aqui a noção de "reuso", termo amplamente utilizado pelos profissionais da computação quando da elaboração de softwares. Nesta tarefa, foram localizados dois instrumentos, um elaborado pela Organização Mundial de Turismo (OMT) e outro pelo Instituto de Estúdios Turísticos do Ministério da Economia da Espanha.

O Tesauro de Turismo y Ocio (OMT, 2001) classifica a área em 19 classes temáticas (termos genéricos): Atividades esportivas, Legislação turística, Ecologia do turismo, Economia do turismo, Instalações turísticas, Movimento turístico, Formação e emprego, Alojamento, Lazer, Acontecimento turístico, Patrimônio turístico, Política turística, Serviços turísticos, Profissionais de turismo, Promoção turística, Ciência e informação, Sociologia do lazer, Turismo setorial e Transporte. Já o Tesauro do Instituto de Estudos Turísticos do Ministério da Economia da Espanha (ESPAÑA, 2003), estrutura a área em 9 classes temáticas (termos genéricos): Organizações turísticas, Turismo e meio social, Patrimônio turístico, Atividades 


\section{TURISMO EM ANÁLISE}

esportivas e recreativas, Serviços turísticos, Economia do turismo, Política turística, Lei, e Educação e formação turística.

Nota-se, em ambos os tesauros, a predominância da abordagem econômica do Turismo, concebida como atividade estreitamente vinculada à noção de crescimento e desenvolvimento econômico. A análise acurada desses dois tesauros mostra que o segundo (ESPAÑA, 2003) se aproxima mais da realidade do estado da arte do conhecimento turístico produzido no Brasil, embora a denominação de alguns termos do primeiro (OMT, 2001) seja mais adequada. Com isso, ambos podem oferecer subsídios à construção preliminar de categorias temáticas (termos maiores) do conhecimento turístico produzido no Brasil.

Como já citado, um tesauro supõe a definição de um esquema global que reflita a natureza do campo científico, suas áreas de especialidade e os campos conexos, ou seja, deve refletir o sistema nocional da área. Nessa medida, propõe-se uma estruturação categórica preliminar do campo do Turismo em 14 classes temáticas (termos ou genéricos), a ser discutida e aprimorada, tomando como referência a produção acadêmica sobre turismo da pesquisa de Rejowski (2010), sua vinculação a termos dos tesauros citados e as particularidades da produção científica no Brasil.

O primeiro grupo compõe-se de seis termos maiores extraídos do tesauro do Instituto de Estudos Turísticos (ESPAÑA, 2003): Atividades esportivas e recreativas, Educação e formação turística, Legislação turística, Serviços turísticos, Patrimônio turístico e Política turística. Os quatro primeiros termos podem ser aplicados como tal sob a ótica das autoras deste artigo; porém os demais merecerem alguns comentários descritos a seguir.

O termo Patrimônio turístico pode ser questionado a princípio, ao se pensar em termos como Oferta turística ou Atração turística. Segundo Vieira Filho (2002), o conceito de patrimônio "é culturalmente construído e, como tal, passível de diferentes percepções e usos por diferentes segmentos sociais" e áreas de estudo. Um desses usos é no Turismo, cujo significado remete aos bens, materiais ou não (tangíveis ou intangíveis), culturais ou naturais, 
tratados comumente no Brasil como recursos e/ou atrativos turísticos ${ }^{5}$. Considerando que o termo já figura em dois tesauros especializados, defende-se a sua adoção como termo genérico.

O termo Política turística não deve abranger o Planejamento turístico, embora nos tesauros consultados (OMT, 2001; ESPAÑA, 2003) isso ocorra: os termos menores Plano turístico e Projeto turístico estão subordinados a esse termo maior. Embora sejam termos próximos, concorda-se com Lohmann e Panosso Netto (2008) de que são distintos, e referenda-se a compreensão de Solha (2011, s. p.) em relação aos seus significados baseados no desenvolvimento do turismo:

Política de turismo - Define como deve ser o desenvolvimento do turismo no destino considerando decisões que podem ter resultados de longo prazo, é determinada em função dos interesses, desejos, valores e cultura da sociedade.

Planejamento turístico - É um processo que tem por objetivo a organização do desenvolvimento do turismo, num horizonte de tempo pré-determinado, com a implementação de ações que podem ter dimensão local, regional, nacional ou internacional. Para tanto considera a situação atual do destino, os objetivos e metas determinados na política de turismo.

Não se adotou o Desenvolvimento turístico como um termo superordenado (genérico), apesar de estudos de Xiao e Smith (2006) que indicam a meta-categoria Desenvolvimento e impactos em artigos publicados no Annals of Tourism Research (ANNALS..., 2003) e o de Santos (2010) que adota a categoria temática Planejamento e desenvolvimento do turismo na análise da produção acadêmica de Mestrados em Turismo de Portugal. Em trabalho de Oliveira e Rejowski (2008), esse termo. analisado enquanto categoria temática, mostrou-se inconsistente no âmbito de um conjunto de dissertações e teses brasileiras. Por esta razão não figura como termo genérico, mas sim como termo específico na presente proposta.

O segundo grupo de termos reúne a adaptação de quatro termos genéricos do tesauro do Instituto de Estudos Turísticos (ESPAÑA. 2003): Organismos turísticos (no lugar de

\footnotetext{
${ }^{5}$ Apesar do termo Atrativo turístico ter sido adotado no Brasil pelos estudiosos do Turismo, percebe-se a sua inadequação gramatical pois indica um substantivo quando na realidade é um adjetivo adjetivado. Lohmann e Panosso Netto (2008) incluem a Atração Turística como um dos conceitos da Teoria do Turismo.
} 


\section{TURISMO EM ANÁLISE}

Organizações turísticas), Estudos econômicos do turismo (no lugar de Economia do turismo), Estudos sociais do turismo (no lugar de Turismo e meio social), Estudos ambientais do turismo (no lugar de Turismo e meio ambiente); e dois termos do tesauro da OMT (2001): Epistemologia do Turismo (no lugar de Ciência e Informação) e Tipologia turística (no lugar de Turismo setorial).

O termo primário Organismos turísticos não deve ser confundido com Serviços turísticos no qual figuram diferentes setores e organizações turísticas como transporte aéreo, agências de turismo e hotéis. Nele classificam-se organismos que atuam no setor como ministério, secretaria, convention bureau, sindicato, associação de classe etc. Conforme Lohmann e Panosso Netto (2008, p. 116-117), tais organismos dividem-se em: “públicos, de economia mista e privados"; "internacionais, nacionais, estaduais (regionais) e municipais"; ou ainda em agências supranacionais, associações de classe, associações de empresas, organismos estatais e organizações não-governamentais.

O termo Estudos ambientais do turismo relaciona-se apenas aos aspectos do ambiente natural (físico) não abarcando todos os aspectos associados ao conceito de meio ambiente. Já o termo Estudos sociais do turismo refere-se a vários campos que enfocam o comportamento e as interações humanas e visões da sociedade humana, incluindo a interface do turismo com a história, geografia, psicologia, sociologia, arqueologia, comunicação, serviço social (saúde e higiene) etc. Com relação ao termo Estudos econômicos do turismo, este substitui o termo Economia do turismo, e inclui todos os aspectos econômicos envolvidos nos estudos turísticos, exceto os administrativos e de gestão que constituem um termo genérico à parte.

Esclarece-se que a opção por esses três termos como Estudos... está baseada no estabelecimento de relações de associação, equivalência e hierarquia configuradas em termos representativos tanto de especialidades turísticas em áreas de estudo tradicionais como Geografia, Sociologia e Antropologia, quanto em áreas emergentes ou interdisciplinares como Ecologia e Saúde Pública, sem enfatizar cada uma delas como um termo superordenado. Defende-se, então, a abordagem interdisciplinar do campo do Turismo, sem negar seu caráter multidisciplinar. 


\section{TURISMO EM ANÁLISE}

O termo Epistemologia do turismo é proposto por ser mais abrangente do que Teoria do Turismo, e face à produção de estudos sobre esse tema no Brasil, tais como os de Möesch (2004), Dencker (2005) e Panosso Netto (2005), além dos estudos já citados acerca da produção científica. Já o termo Tipologia turística abrange os variados tipos de turismo presentes na literatura científica, que tipificam a oferta e a demanda turística a partir de diferentes critérios (turismo de lazer, turismo rural, turismo juvenil etc.).

Por fim, propõem-se dois novos termos genéricos em face da evolução do ensino superior e da produção científica em Turismo no Brasil: Planejamento turístico, relacionado ao preparo e à organização, e Gestão do turismo, à implementação, ao aprimoramento e ao avanço (SOLHA, 2011). A trajetória do ensino superior no Brasil a partir da década de 1970 se fundamentou no planejamento como vetor de desenvolvimento não apenas econômico, integrando a gestão a partir da década de 1990. Essas abordagens coexistem na atualidade consolidando propostas curriculares de cursos de graduação e apresentando-se em várias linhas de pesquisa de mestrados em Turismo e Hospitalidade (REJOWSKI, 2010).

O termo Planejamento turístico já foi explicado anteriormente, não havendo necessidade de ser retomado. Por outro lado, o termo Gestão do turismo refere-se ao termo em inglês Tourism management, compreendido como gestão da atividade turística em destinos, empresas, organizações etc., no âmbito público e/ou privado.

Após as considerações conceituais sobre as classes temáticas que podem representar inicialmente conceitos abrangentes do Turismo, apresenta-se o quadro 2 com os termos genéricos (TG) propostos e suas respectivas fontes, além alguns exemplos de termos específicos (TE). Os TE figuram sem ordenação e podem se repetir em vários TG como, por exemplo, o caso de Impacto do turismo. 
Quadro 2 - Proposta de termos genéricos para o mapeamento do conhecimento turístico e exemplos extraídos da literatura científica

\begin{tabular}{|c|c|c|}
\hline $\begin{array}{c}\text { Proposta preliminar de Termos } \\
\text { genéricos (TG) }\end{array}$ & Fonte & $\begin{array}{l}\text { Exemplos de termos específicos } \\
\text { (OMT, 2001; ESPAÑA, 2003; } \\
\text { REJOWSKI, 2010) }\end{array}$ \\
\hline $\begin{array}{l}\text { 1. Atividades esportivas e } \\
\text { recreativas }\end{array}$ & España (2003) & $\begin{array}{l}\text { Caminhada } \\
\text { Excursionismo }\end{array}$ \\
\hline $\begin{array}{l}\text { 2. Educação e formação } \\
\text { turística }\end{array}$ & España (2003) & $\begin{array}{l}\text { Ensino superior } \\
\text { Formação profissional } \\
\text { Instituições educacionais }\end{array}$ \\
\hline 3. Epistemologia do turismo & Panosso Netto (2005) & $\begin{array}{l}\text { Interdisciplinaridade } \\
\text { Produção científica } \\
\text { Teoria do turismo }\end{array}$ \\
\hline $\begin{array}{l}\text { 4. Estudos ambientais do } \\
\text { turismo }\end{array}$ & Rejowski (2010) & $\begin{array}{l}\text { Conservação do meio ambiente } \\
\text { Diagnóstico ambiental } \\
\text { Impacto do turismo }\end{array}$ \\
\hline $\begin{array}{l}\text { 5. Estudos econômicos do } \\
\text { turismo }\end{array}$ & Rejowski (2010) & $\begin{array}{l}\text { Análise econômica } \\
\text { Consumo turístico } \\
\text { Gasto turístico } \\
\text { Impacto do turismo } \\
\text { Investimento turístico } \\
\text { Mercado turístico }\end{array}$ \\
\hline 6. Estudos sociais do turismo & Rejowski (2010) & $\begin{array}{l}\text { Antropologia do turismo } \\
\text { Comunicação } \\
\text { Emprego } \\
\text { Geografia do turismo } \\
\text { História do turismo } \\
\text { Hospitalidade } \\
\text { Lazer } \\
\text { Pesquisa de mercado } \\
\text { Saúde e higiene } \\
\text { Sociologia do turismo }\end{array}$ \\
\hline 7. Gestão turismo & (Rejowski, 2010) & $\begin{array}{l}\text { Produto turístico } \\
\text { Marketing turístico } \\
\text { Imagem } \\
\text { Segmentação } \\
\text { Competitividade } \\
\text { Qualidade } \\
\text { Estratégia } \\
\text { Gestão financeira }\end{array}$ \\
\hline 8. Legislação turística & OMT (2001) & $\begin{array}{l}\text { Legislação internacional } \\
\text { Legislação trabalhista } \\
\text { Defesa do consumidor } \\
\text { Empresa }\end{array}$ \\
\hline 9. Organismos turísticos & $\begin{array}{l}\text { Lohmann e Panosso Netto } \\
\text { (2008) }\end{array}$ & $\begin{array}{l}\text { Associações de classe } \\
\text { Organismos internacionais } \\
\text { Organismos nacionais } \\
\text { Organizações não governamentais }\end{array}$ \\
\hline
\end{tabular}




\begin{tabular}{|c|c|c|}
\hline 10. Patrimônio turístico & OMT (2001); España (2003) & $\begin{array}{l}\text { Arquitetura e urbanismo } \\
\text { Destino turístico } \\
\text { Patrimônio cultural } \\
\text { Patrimônio natural } \\
\text { Recurso turístico } \\
\text { Regiões turísticas } \\
\text { Rota turística }\end{array}$ \\
\hline 11. Planejamento turístico & Rejowski (2010) & $\begin{array}{l}\text { Diagnóstico turístico } \\
\text { Inventário da Oferta } \\
\text { Desenvolvimento turístico } \\
\text { Programa de ação } \\
\text { Projeto turístico }\end{array}$ \\
\hline 12. Política turística & España (2003) & $\begin{array}{l}\text { Cooperação internacional } \\
\text { Fomento do turismo } \\
\text { Política pública }\end{array}$ \\
\hline 13. Serviços turísticos & OMT (2001); España (2003) & $\begin{array}{l}\text { Agência de turismo } \\
\text { Alimentos e Bebidas } \\
\text { Gastronomia } \\
\text { Hotelaria } \\
\text { Meio de hospedagem } \\
\text { Segunda residência } \\
\text { Tecnologia da informação } \\
\text { Transporte }\end{array}$ \\
\hline 14. Tipologia turística & Rejowski (2010) & $\begin{array}{l}\text { Ecoturismo } \\
\text { Turismo de massa } \\
\text { Turismo internacional } \\
\text { Turismo juvenil } \\
\text { Turismo sustentável } \\
\text { Turismo urbano }\end{array}$ \\
\hline
\end{tabular}

Fonte: elaboração própria.

Para aprimorar a proposta apresentada faz-se necessária, primeiramente, a validação dos termos genéricos e de seus respectivos termos específicos, relacionados e equivalentes, e, secundariamente, a substituição ou não de termos propostos, definindo relações de hierarquia, associação e equivalência. Outras questões referem-se à análise detalhada de: a) termos polilexicais, que incluem preposições - do(a), em. no(a) - e de termos adjetivados; b) termos compostos com a conjunção aditiva "e", como Educação e formação em turismo. Há ainda a necessidade de se testar a estrutura preliminar em um maior conjunto de documentos representativos da produção científica brasileira em Turismo, em especial as dissertações e teses, e os artigos de periódicos científicos. E por fim há que se conceituar cada um dos termos genéricos e identificar a sua abrangência por meio dos termos específicos, em consonância com o estado da arte do conhecimento turístico produzido no Brasil. 


\section{TURISMO EM ANÁLISE}

\section{Considerações Finais}

As reflexões acima marcam o início de um processo de estudo e pesquisa em prol da construção de um Tesauro Brasileiro de Turismo, apto a responder às especificidades do campo científico do Turismo, com base no conhecimento do turismo produzido em dissertações e teses no Brasil, e aporte teórico da Análise documentária, do campo da Ciência da Informação.

Os benefícios da construção e uso de um tesauro específico são evidentes: as bases de dados da produção em Turismo ganharão em qualidade porque os dados inseridos serão uniformes, do ponto de vista temático. Os pesquisadores serão beneficiados porque as buscas de informação em repositórios fornecerão resultados mais precisos, o que deverá facilitar a identificação do estado da arte da pesquisa na área e, em decorrência, a proposição de políticas de pesquisa para a área.

De outro lado, dados organizados de forma sistêmica são instrumentos poderosos de comunicação entre pares, como também de intercâmbio entre diferentes repositórios de informação. A disseminação das informações poderá atingir um novo patamar de qualidade com o uso de uma linguagem padronizada e compartilhada. O desenvolvimento de um Tesauro Brasileiro de Turismo responde, portanto, a demandas concretas de pesquisadores da área.

Mas tem-se claro que o caminho para iniciar a elaboração de um Tesauro é designar os termos a partir de conceitos abrangentes que representam apropriadamente um domínio específico do conhecimento, no caso do Turismo. Somente assim poder-se-á realizar com rigor a tarefa de organizar lógica e semanticamente os seus termos.

Assim, é imprescindível o engajamento de pesquisadores de Turismo nesse processo de forma participativa para o que são muito bem vindas críticas e sugestões, comentários e propostas, estudos e trabalhos conjuntos ou isolados. Aqui, mais uma vez, destaca-se a importância do desenvolvimento de Estudos Críticos do Turismo, principalmente na análise e validação de terminologias, conceitos, teorias e metodologias, com importantes contribuições à elaboração 
de um tesauro específico. Fica lançado o desafio e a esperança de finalizar, em um futuro próximo, o Tesauro Brasileiro em Turismo.

\section{Referências}

ANSI/NISO Z 39.19:2005. Guidelines for the construction, format, and management of monolingual controlled vocabularies. Bethesda: NISO Press, 2005.

ANNALS OF TOURISM RESEARCH. Index (1973-2003). Annals of Tourism Research, v. 30, n. 4, oct. 2003, p. 983-1048(66)

AUSTIN, Derek. Diretrizes para o estabelecimento e desenvolvimento de tesauros monolingues. Brasília: IBICT, 1993.

BACAL, Sarah Strachmann. Lazer e o universo dos possiveis. São Paulo: Aleph, 2003.

BASTOS, Sênia. Produção acadêmica do mestrado em Hospitalidade. Revista Hospitalidade, São Paulo, ano II, n. 1, p. 89-95, 2005.

BASTOS, Sênia. A produção científica do Mestrado em Hospitalidade (2002-2008). Revista Hospitalidade. São Paulo, ano V, n. 2, p. 120-132, jul.-dez. 2008.

BENI, Mário Carlos. Sistema de turismo: construção de um modelo teórico referencial para a aplicação na pesquisa em Turismo. Tese (Doutorado em Ciências da Comunicação) - Universidade de São Paulo, São Paulo, 1988.

BENI, Mário Carlos. Análise estrutural do turismo. São Paulo: Senac, 2001.

BOTTERILL, David. A survey of doctoral theses accep universities in the UK and Ireland related to tourism, 1990-1999. Tourist Studies, v. 2, n. 3, p. 283-311, 2002.

CACALY, Serge, LE COADIC, Yves. F.; MELOT, Michel, PORMART, Paul-Dominique, SUTTER, Eric. Dictionnaire encyclopédique de l' information et de la documentation. Paris: Nathan, 2001.

CINTRA, A. M. M. et al. Para entender as linguagens documentárias. São Paulo: Polis/APB, 2002.

DENCKER, Ada de F.M. Pesquisa como base a construção teórica no campo do turismo e da hospitalidade. Revista Hospitalidade, São Paulo, ano 2, n. 1, p. 55-67, $1^{\circ}$ sem. 2005.

ESPAÑA. MINISTÉRIO DE ECONOMÍA. Secretaria de Estado de Comércio y Turismo. Secretaria General de Turismo. Instituto de Estudios Turísticos. Tesauro - turismo (español-ínglês-francês) Centro de Documentación Turística de España: Madrid, 2003.

FARRELL, Bryan H.; TWINING-WARD, Louise. Un nuevo concepto del turismo. Annals of Tourism Research, v. 6, n. 1, 2004, p. 65-90

FEDRIZZI, Valéria Luiza Ferreira. Conhecimento Gerado no Programa de Mestrado em Hospitalidade da Universidade Anhembi Morumbi. Dissertação (Mestrado em Hospitalidade) Universidade Anhembi Morumbi, São Paulo, 2008.

FIGUEIREDO, Franciele B.; BACCON, Melissa; REJOWSKI, Mirian. Perfil e "performance" dos mestres em turismo da Universidade de Caxias do Sul - 2002 a 2006. In: SEMINÁRIO DA ASSOCIAÇÃO NACIONAL DE PESQUISA E PÓS-GRADUAÇÃO EM TURISMO, IV, 2007. Anais ... São Paulo:. Editora Aleph, 2007. (cd-rom) 
FERNÁNDEZ FUSTER, Luiz. Teoria y técnica del turismo. Madrid: Nacional, 1971.

GALEMBERCK, F. Sem avaliação, sem progresso. Ciência e Cultura, v. 19, n. 9, p 627-628, 1990.

GOMES, Cristina Marques. Pesquisa cientifica em lazer no Brasil: bases documentais e teóricas. Dissertação (Mestrado em Ciências da Comunicação) - Universidade de São Paulo, São Paulo, 2004.

GOMES, Hagar Espanha. Elaboração de tesauro documentário: aspectos teóricos e práticos. Rio de Janeiro, 1996a. (Mimeo)

GOMES, Hagar Espanha. Classificação, tesauro e terminologia: fundamentos comuns. BITI, 1996b. Disponível em: <http://www.conexaorio.com/biti/tertulia/tertulia.htm>, acesso em: mar. 2010.

HALL, Michael. Tourism as a subject of a postgraduate dissertation in Australia. Annals of Tourism Research, Menomonie, v. 18, n. 3, p. 520-523, 1991.

JAFARI, Jafar. AASER, Dean. Tourism as the subject of doctoral dissertations. Annals of Tourism Research, Menomonie, v.15, p. 407-429, 1988.

JAFARI, Jafar; RITCHIE, John R. Brent. Toward a framework for the tourism education. Problems and prospects. Annals of Tourism Research. Great Britain: Pergamon, v.8, n.1, p. 13-34, 1981.

KOBASHI, N.Y. Análise Documentária e representação da informação. Revista Informare, Rio de Janeiro, v. 2, n. 2, p. 5-27, 1996.

KOBASHI, Nair Yumiko. Fundamentos semânticos e pragmáticos da construção de instrumentos de representação de informação. Rio de Janeiro: Datagrammazero Revista de Ciência da Informação, v.8, n.6, dez, 2007.

LOHMANN, Guilherme; PANOSSO NETTO, Alexandre. Teoria do turismo. São Paulo: Aleph, 2008.

MCBETH, Jim. Towards an ethics platform for tourism. Annals of Tourism Research, Elsevier, v. 32, n. 4, p. 962-984, oct. 2005.

MÖESCH, Marutschka M. Construção metodológica dialética: por uma epistemologia do Turismo. Dissertação (Mestrado em Comunicação Social) - Pontifícia Universidade Católica do Rio Grande do Sul, Porto Alegre, 1999.

MÖESCH, Marutschka M. Epistemologia social do turismo. São Paulo. Tese (Doutorado em Ciências da Comunicação) - Universidade de São Paulo, São Paulo, 2004.

MOOM, Christiane F. O conhecimento científico em turismo no Brasil: curso de pós-graduação (stricto sensu) - período de 2000 a 2006. Dissertação (Mestrado em Ciência da Informação) Universidade Federal de Florianópolis, Florianópolis, 2009.

MOOM; Christiane F. SANTOS, Raimundo M. dos. O estado da arte da área de pesquisa do turismo no Brasil: período de 2000 a 2006. Revista Turismo \& Desenvolvimento. Aveiro, v. 1, n. 13-14, p, 373-385, 2010.

OLIVEIRA, Jurandir Chaves de; REJOWSKI, Mirian. Teses em turismo no Brasil: categoria temática "desenvolvimento do turismo". In: CONGRESSO BRASILEIRO DE CIÊNCIAS DA COMUNICAÇÃO, XXXI, 2008, Natal. Anais do XXXI INTERCOM - Mídia, ecologia e sociedade. São Paulo: Intercom, v. 1. p. 1-14, 2008 (cd-rom).

OMT - ORGANIZACIÓN MUNDIAL DEL TURISMO. Secretaría de Estado de Turismo de Francia. Tesauro de turismo y ocio. Madrid: OMT, 2001, v. 1-5. 
PANOSSO NETTO, Alexandre. Fenomenologia do turismo. Uma proposta de construção epistemológica. Tese (Doutorado em Ciências da Comunicação) - Universidade de São Paulo, São Paulo, 2005.

PINTO, Débora B.; BABINSKI, Luciana R. Produção acadêmica do mestrado em turismo da Universidade de Caxias do Sul: estudo comparativo das dissertações (2002 a 2004 - 2004 a 2005). CONFERÊNCIA DA AMFORHT PARA AMÉRICA LATINA, III, São Paulo, 2006. Anais.... SENAC-SP: São Paulo, 2006 (cd-rom).

POSSAMAI, Ana Maria de Paris; MARINHO, Marcela Ferreira; SANTOS, Marcia Maria Cappellano dos. Pesquisa em Turismo: Panorama das Teses de Doutorado produzidas no Brasil de 2005 a 2007. In: SEMINÁRIO DA ASSOCIAÇÃO NACIONAL DE PESQUISA E PÓS-GRADUAÇÃO EM TURISMO, VI, São Paulo, 2009. Anais ... São Paulo: Aleph, 2009. (cd-rom).

REJOWSKI, M. Realidade turística nas pesquisas científicas: visão de pesquisadores e profissionais. Tese (Livre Docência) - Universidade de São Paulo, São Paulo, 1997. 2v.

REJOWSKI, Mirian. Pesquisa acadêmica em turismo no Brasil (1975 a 1992): configuração e sistematização documental. Tese (Doutorado em Ciências da Comunicação) - Universidade de São Paulo, São Paulo, 1993. 2v.

REJOWSKI, Mirian. Pesquisa cientifica em turismo no Brasil (1990 a 2005). Comunicação, produtividade e posicionamento. Relatório de Pesquisa (PQ CNPq) - Universidade Anhembi Morumbi, São Paulo: 2010.

SAKATA, M.C.G. Tendências metodológicas da pesquisa acadêmica em turismo. São Paulo, 2002. Dissertação (Mestrado em Ciências da Comunicação) - Universidade de São Paulo.

SANTOS, Jorge H. P. A, dos. A investigação turística em Portugal. Dissertação (Mestrado em Gestão e Desenvolvimento Turístico) - Universidade de Aveiro, Aveiro, 2010.

SCHLÜTER, Regina. Investigación em turismo y hotelería. Buenos Aires: CIET, 2000.

SOGAYAR, Roberta L. Hospitalidade no ensino superior em turismo: estudo de caso do programa tourism education future iniciative. Dissertação (Mestrado em Hospitalidade) - Universidade Anhembi Morumbi, São Paulo, 2010.

SOLHA, Karina T. Termo planejamento e gestão do turismo. (Correspondência por email com Mirian Rejowski) 23 maio e 25 ago. 2011, s. p.

SPOLON, Ana Paula Garcia. MOTODA, Mauro. Novos caminhos da pesquisa acadêmica: a produção brasileira recente em turismo e hospitalidade. In: SEMINÁRIO DA ASSOCIAÇÃO NACIONAL DE PESQUISA E PÓS-GRADUAÇÃO EM TURISMO, V, Belo Horizonte, 2008. Anais... São Paulo: Aleph, 2008, p. 1- 14 (cd-rom).

VIEIRA FILHO, Nelson A. Quadros. Patrimônio, turismo e sustentabilidade, Reuna. Belo Horizonte, v. 7, n.4, p. 11-24, 2002.

XIAO, Honggen; SMITH, Stephen L.J. La génesis de la investigación turística: el análisis de una publicación de ciencias sociales. Annals of Tourism Research en Español, Universidad de les Illes Baleares, España, v.8, n.1, p. 131-151, 2006.

\section{Recebido em: 26/08/2011}

Aprovado em: 07/10/2011 